\title{
A Commitment to Change: Revision of HCFA's RAI
}

\author{
John N. Morris, PhD, Sue Nonemaker, RN, MS, ${ }^{\dagger}$ Katharine Murphy, RN, MS*, \\ Catherine Hawes, $P h D,{ }^{\ddagger}$ Brant E. Fries, $P h D,{ }^{`}$ Vincent Mor, $P h D, "$ and Charles Phillips, $P h D^{\|}$
}

OBJECTIVE: To describe the reliability of new assessment items and their clinical utility as judged by experienced nurse assessors, based on the results from the field test of Version 2.0 of the Resident Assessment Instrument (RAI).

DESIGN: Independent dual assessment of residents of nursing facilities by staff nurses using a draft of Version 2.0 of the minimum data set (MDS).

SETTING AND PARTICIPANTS: A total of 187 randomly selected residents from 21 nursing homes in seven states volunteered to test Version 2.0 of the MDS.

MEASUREMENT: The full array of MDS assessment items included measures in the following areas: Background information, cognitive patterns, communication/hearing, vision, mood and behavior, psychosocial well-being, physical functioning and structural problems, continence, disease diagnoses, health condition, oral/nutritional status, dental status, skin condition, activity pursuit patterns, medications, special treatments and procedures, and discharge potential and overall status.

RESULTS: Evaluative data address issues of MDS item utility and reliability. For new items, almost all achieved a reasonably high-weighted Kappa interrater reliability; revised items also surpassed earlier items, and with the updated training materials, even the non-changed items had higher average reliability levels. Based on the success of the field test and the positive response of the industry, Version 2.0 of the RAI has been adopted, and HCFA has initiated a more long-range process to update further the RAI when necessary.

CONCLUSION: Findings support the reliability and clinical utility of the new and revised assessment items incorporated by HCFA in Version 2.0 of the MDS. J Am Geriatr Soc 45:1011-1016, 1997.

\footnotetext{
From the "Hebrew Rehabilitation Center for Aged, HRCA Research and Training Institute, Boston, Massachusetts; ${ }^{\dagger}$ Health Care Financing Administration, Nursing Home Branch, Baltimore, Maryland; $\ddagger$ Research Triangle Institute, Research Triangle Park, North Carolina; SInstitute of Gerontology and School of Public Health, University of Michigan and VA Medical Center, Ann Arbor, Michigan; and "Center for Gerontology and Health Care Research, Brown University, Providence, RI; "Myers Research Institute, Menorah Park Center For Aging, Beachwood, Ohio.

This research was supported by a contract from the Health Care Financing Administration, Contract \#500940058.

Address correspondence to John N. Morris, PhD, Hebrew Rehabilitation Center for Aged, HRCA Research and Training Institute, 1200 Centre St., Boston, MA 02131.
}

Gince 1991, the nursing home Resident Assessment Instrument $\mathcal{S}$ (RAI) has been mandated for use in federally certified nursing facilities in the United States. Under the Nursing Home Reform Act, which was embedded in the Omnibus Budget Reconciliation Act (OBRA) of 1987, and under Health Care Financing Administration (HCFA) guidelines, the RAI is designed to provide a comprehensive, accurate, standardized assessment of a resident's functional capabilities. ${ }^{1-3}$ In line with this goal, a series of papers have documented the inter-rater reliability of the minimum data set (MDS) items, ${ }^{1-3}$ including tests of the level of agreement between research and staff nurse assessors. ${ }^{4}$ In addition, there have been a number of reports that have documented the validity of the MDS items and summary scales derived from these items in relation to established clinical and research instruments. ${ }^{5-8}$

In late 1992, with a Notice of Proposed Rulemaking, HCFA raised the possibility of revising and improving the RAI system. Comments were solicited regarding MDS items to be modified, added or deleted, assessment areas requiring additional clarification, Resident Assessment Protocols (RAPs) for tracking key problem areas that should be modified, and the need for RAPs that went beyond the 18 in the current RAI system. The suggestions for revision to the MDS were reviewed by a clinical panel of State representatives and members of the HRCA technical support contract team.

\section{See also editorials pp. 975,1025 , and 1027}

As a result of this effort, revised and new items were constructed, and a multi-state field test was initiated. The new MDS items describe newly emerging resident subgroups (such as individuals receiving subacute post-hospital care), ensure a "crosswalk" with related federal systems (such as the MDS-based Quality Indicators and the Resource Utilization Groups (RUG-III) case mix system), and serve to improve the reliability of the item set. Input was solicited from industry representatives, government officials (at the $\mathrm{Na}$ tional, Regional, and State levels), staff of the Department of Veterans Affairs who were involved in an experimental implementation of the MDS, the full RAI Advisory Committee, an international consortium of researchers (interRAI) with experience implementing the RAI abroad, members of the original MDS development team, and experts in specialized assessment area.

As a result of this revision and the subsequent evaluation process, in April 1995 HCFA formally designated a new version of the MDS (Version 2.0) by issuing State Operations Manual Transmittal No. 272 that mandated use of Version 2.0 of the RAI as a replacement for the original RAI as required by OBRA ' 87 . 
Table 1. Reliability of Selected New Items Added to Version 2.0 of the MDS

\begin{tabular}{|c|c|c|}
\hline MDS Section & New Items & $\begin{array}{l}\text { Weighted Kappa } \\
\text { Interrater Reliability }\end{array}$ \\
\hline Customary routine & $\begin{array}{l}\text { Uses tobacco products at least daily } \\
\text { Bathing in p.m. }\end{array}$ & $\begin{array}{l}.79 \\
.76\end{array}$ \\
\hline $\begin{array}{l}\text { Physical functioning and } \\
\text { structural problems }\end{array}$ & $\begin{array}{l}\text { Walk in room } \\
\text { Walk in corridor } \\
\text { Self-performance-locomotion off unit } \\
\text { Test for balance while standing } \\
\text { Test for balance while sitting }\end{array}$ & $\begin{array}{l}.92 \\
.89 \\
.89 \\
.86 \\
.76\end{array}$ \\
\hline Disease diagnoses/Infections & $\begin{array}{l}\text { Deep vein thrombosis } \\
\text { Transient ischemic attack } \\
\text { Schizophrenia } \\
\text { HIV Infection }\end{array}$ & $\begin{array}{r}.66 \\
.74 \\
.80 \\
1.00\end{array}$ \\
\hline Skin conditions & $\begin{array}{l}\text { Stage } 1 \text { Pressure Ulcer } \\
\text { Stage } 2 \text { Pressure Ulcer } \\
\text { Stage } 3 \text { Pressure Ulcer } \\
\text { Stage } 4 \text { Pressure Ulcer } \\
\text { Rashes, e.g., intertrigo, eczema, drug rash, heat rash, herpes zoster } \\
\text { Corns, callouses, bunions, etc. } \\
\text { Received preventative or protective skin care } \\
\text { Nails/calluses trimmed during last } 90 \text { days }\end{array}$ & $\begin{array}{r}.39 \\
.71 \\
.85 \\
1.00 \\
.60 \\
.52 \\
.67 \\
.44\end{array}$ \\
\hline $\begin{array}{l}\text { Discharge potential and } \\
\text { overall status }\end{array}$ & $\begin{array}{l}\text { Resident expresses/indicates preference to return to the community } \\
\text { Resident has a support person who is positive towards discharge } \\
\text { Overall change in care needs }\end{array}$ & $\begin{array}{l}.77 \\
.87 \\
.60\end{array}$ \\
\hline
\end{tabular}

In this article, we present data from the field trial, including information on item reliability, the assessors' views of the clinical utility of new items, and the added assessment burden they represent.

\section{METHODS}

Thirty facilities, in seven states, were selected to participate in the field trial. These facilities were identified through an industry outreach self-referral process. Of the 30 facilities, 21 tested the full MDS, and it is the results of this aspect of the field test that are now being described.
In each of the 21 field test homes, two nurse assessors with prior MDS experience independently completed assessments of a randomly selected sample of residents. In addition, at the end of this assessment process, these $\mathbf{4 2}$ nurse assessors answered a series of questions regarding their views of the new and revised MDS items.

The nurse assessors prepared for their role in testing Version 2.0 of the MDS by watching a brief training video, reviewing the User's Manual that described the revised Version 2.0 instrument, and completing a preliminary practice assessment following the specified data acquisition and cod- 
ing processes. They were then debriefed in a telephone conversation with project staff to ensure that they were prepared to complete the MDS assessments in accordance with the new item configurations.

Then, the two nurse assessors at each site completed independent assessments of a random sample of residents. Ten cases were scheduled at each home. Of the potential pool of 210 cases, dual assessments were actually completed for 187 cases, an average of 8.9 dual assessments per facility. In completing these cases, the two nurse assessors at each facility did not discuss the residents nor their findings. After completing the assessments, the assessors completed a form designed by investigators to provide information on the time involved in completing the revised MDS assessment and their opinion of the new and revised items.

The data that emerged from this field test permitted a comprehensive evaluation of the reliability and utility of new and revised MDS items and the added time required to complete the assessments. Thus, findings are reported based both on the opinions of the nurse assessors regarding Version 2.0 of the MDS and on the item reliability within the 187 person dually assessed resident sample. In the reliability analyses, weighted Kappa values are presented, and to put these values into perspective, Kappa values lower than 0.4 indicate poor reliability, .40 to .75 is considered adequate, and .75 or greater is considered evidence of excellent reliability. ${ }^{9}$

\section{RESULTS}

\section{Sample Description}

The average age of the residents in the reliability sample is 80.6 years, $71.7 \%$ are female, and $61.8 \%$ have problems with short-term memory. In regard to ADLs, $44.4 \%$ are dependent in dressing, $34.2 \%$ in locomotion, and $20.3 \%$ in eating.

\section{Reliability of New and Revised Items}

Almost all of the newly added items (e.g., measures of pain, infection, foot care, service utilization, drug utilization, and discharge status) achieved adequate weighted Kappa interrater reliability levels (see Table 1).

Reliability values for items that were revised in Version 2.0 of the MDS (e.g., items for mood, behavior, delirium, and change in status indicators over the previous 90 -day period) were significantly higher than the reliabilities for the items they replaced (see Table 2). In addition, for the $82 \mathrm{MDS}$ items that did not change from the original version to Version 2.0, for which there were changes in the process instructions, item definitions, or examples, there was an $18 \%$ increase in average weighted Kappa inter-rater reliability levels, going from an average of .67 in the original MDS to .79 in the MDS Version 2.0. Using the standards set by Fleiss for Kappa reliabilities, this represents a movement from adequate reliability to excellent reliability.

\section{Staff Appraisal of the MDS 2.0}

Most nurse assessors made positive, reaffirming statements $(60.6 \%)$ regarding the overall changes to the MDS. The new MDS items were described as helpful, and the revised definitions were described as clearer than the original. Only $15 \%$ of the nurse assessors described the changes negatively, citing added complexity and an increased time commitment to complete Version 2.0.

For care planning purposes, $7 \%$ said that the new items had no utility, $14.3 \%$ said that at least some items had care planning utility, and $78.6 \%$ were very positive in assessing the care planning utility of the full set of new MDS items. Of those who said that they saw utility in the new items, $46 \%$ referenced specific new or revised items; the most commonly item sets were Pain, Mood, Delirium, and Pressure Ulcers.

Nurse assessors with positive views liked the broader and more complete definitions for many MDS items and that the revised MDS permitted a more individualized view of the resident and, therefore, facilitated the care planning process. At the same time, nurse assessors who responded that they did not believe that the new MDS items provided more

Table 2. Reliability of Selected Revised Items in Version 2.0 of the MDS

\begin{tabular}{|c|c|c|c|c|c|}
\hline \multirow[b]{2}{*}{ MDS Section } & \multirow[b]{2}{*}{ Key Types of Indicators Changed } & \multicolumn{2}{|c|}{ Number of Items } & \multicolumn{2}{|c|}{$\begin{array}{l}\text { Average Weighted } \\
\text { Kappa Reliability }\end{array}$} \\
\hline & & $\begin{array}{l}\text { in } \\
\text { Original } \\
\text { MDS }\end{array}$ & $\begin{array}{l}\text { in MDS } \\
\text { Version } \\
2.0\end{array}$ & $\begin{array}{l}\text { in } \\
\text { Original } \\
\text { MDS }\end{array}$ & $\begin{array}{c}\text { in MDS } \\
\text { Version } \\
2.0\end{array}$ \\
\hline Cognitive patterns & $\begin{array}{l}\text { Indicators of delirium: } \\
\text { Dichotomous } \\
\text { New trichotomous version }\end{array}$ & $\begin{array}{l}5 \\
0\end{array}$ & $\begin{array}{l}6 \\
6\end{array}$ & .09 & $\begin{array}{l}.33 \\
.68\end{array}$ \\
\hline \multirow{2}{*}{$\begin{array}{l}\text { Physical functioning and } \\
\text { structural problems }\end{array}$} & Task segmentation & 1 & 1 & .29 & .68 \\
\hline & $\begin{array}{l}\text { Change in ADL performance } \\
\text { Limitation in range of motion }\end{array}$ & $\begin{array}{l}1 \\
4\end{array}$ & $\begin{array}{l}1 \\
6\end{array}$ & $\begin{array}{l}.52 \\
.67\end{array}$ & $\begin{array}{l}.69 \\
.71\end{array}$ \\
\hline
\end{tabular}


detailed information tended to see no benefit from the adoption of these items.

The nurse assessors participating in the 21-site field test were also asked to indicate which of the new items they valued. Table 3 summarizes these results. In most areas, more than $80 \%$ of the nurse assessors recommended adding the new items being tested. In only two areas did this percentage fall to less than two-thirds. These exceptions were: special population measures $(58.8 \%)$ and foot care $(58.8 \%)$. The highest proportion of recommendations for outright exclusion of new items (representing the recommendation of about 1 in every 4 of the nurse assessors) were for items measuring hospital stays, emergency room visits, physician visits/orders, and foot care.

In deciding whether to include new MDS items, there was also a recognition of the need to consider possible tradeoffs between the value of an item and the time required to acquire the information. To test this issue, the nurse assessors were asked to indicate which item sets substantively added time to the assessment, i.e., those representing new areas of inquiry where the assessor could not draw easily on the ongoing data acquisition procedures. Table 4 lists areas where at least one-third of the assessors reported that more time was required to complete the items.

Table 3. Nurse Assessors' Opinion of Whether Proposed New/Revised Items Should Be Kept in Version 2.0 of the MDS*

\begin{tabular}{|c|c|c|c|}
\hline Item & $\begin{array}{l}\% \text { of Nurses Who } \\
\text { Would Add Item to } \\
\text { Instrument }\end{array}$ & $\begin{array}{l}\% \text { of Nurses Who } \\
\text { Would Add if Item } \\
\text { Were Altered Slightly }\end{array}$ & $\begin{array}{l}\% \text { of Nurses Who } \\
\text { Would Not Add Item } \\
\text { to Instrument }\end{array}$ \\
\hline \multicolumn{4}{|l|}{ Identification information } \\
\hline Education level & $70.6 \%$ & $29.4 \%$ & $0.0 \%$ \\
\hline Special population $\dagger$ & 58.8 & 23.5 & 17.7 \\
\hline Customary routine (Bathing in pm) & 94.1 & 5.9 & 0.0 \\
\hline Reason for assessment & 94.1 & 0.0 & 5.9 \\
\hline Self or family pays for care & 70.5 & 5.9 & 23.5 \\
\hline Durable power of attorney & 88.2 & 5.9 & 5.9 \\
\hline \multicolumn{4}{|l|}{ Cognitive patterns } \\
\hline Indicators of delirium & 88.2 & 5.9 & 5.9 \\
\hline Change in cognitive status & 88.2 & 5.9 & 5.9 \\
\hline Communication (Two items) & 94.1 & 5.9 & 0.0 \\
\hline \multicolumn{4}{|l|}{ Physical functioning } \\
\hline Locomotion off unit & 88.2 & 11.8 & 0.0 \\
\hline Body control and range of motion & 82.4 & 17.6 & 0.0 \\
\hline Modes of locomotion-transfer & 100.0 & 0.0 & 0.0 \\
\hline Task segmentation & 88.2 & 11.8 & 0.0 \\
\hline Change in ADL function & 94.1 & 5.9 & 0.0 \\
\hline \multicolumn{4}{|l|}{ Psychological well-being } \\
\hline Unsettled relationship & 100.0 & 0.0 & 0.0 \\
\hline Mood indicators & 94.1 & 0.0 & 5.9 \\
\hline Behavioral symptoms & 94.1 & 0.0 & 5.9 \\
\hline Diseases (New diseases/Infections) & 82.3 & 5.9 & 11.8 \\
\hline \multicolumn{4}{|l|}{ Health and other conditions } \\
\hline New conditions & 64.7 & 17.6 & 17.6 \\
\hline Pain & 100.0 & 0.0 & 0.0 \\
\hline Weight change & 94.1 & 5.9 & 0.0 \\
\hline Parenteral or enteral intake & 82.3 & 11.8 & 5.9 \\
\hline Ulcers and skin treatments & 94.1 & 5.9 & 0.0 \\
\hline Foot care & 58.8 & 17.6 & 23.5 \\
\hline \multicolumn{4}{|l|}{ Treatments } \\
\hline New medication items & 100.0 & 0.0 & 0.0 \\
\hline Special treatments & 82.3 & 11.8 & 5.9 \\
\hline Interventions for mood, behavior & 70.6 & 11.8 & 17.6 \\
\hline Rehabilitative/Restorative care & 88.2 & 11.8 & 0.0 \\
\hline Bed rails & 82.3 & 11.8 & 5.9 \\
\hline Hospital stay & 70.6 & 5.9 & 23.5 \\
\hline Emergency room visit & 70.6 & 5.9 & 23.5 \\
\hline Physician visits/orders & 64.7 & 11.8 & 23.5 \\
\hline Discharge potential & 64.8 & 17.6 & 17.6 \\
\hline Overall change in level of care & 94.1 & 5.9 & 0.0 \\
\hline
\end{tabular}

- Based on assessment of 42 nurse assessors.

+ Item NOT included in HCFA's official release of Version 2.0 of the MDS 
Table 4. Items Where One or More Nurse Assessors Thought It Took Extra Time to Gather Information for the Assessment

\begin{tabular}{lccc}
\hline \multicolumn{1}{c}{ Assessment Area } & $\begin{array}{c}\text { No. of New/Revised } \\
\text { Items }\end{array}$ & $\begin{array}{c}\text { \% Stating Item(s) Added } \\
\text { Time to Assessment }\end{array}$ & $\begin{array}{c}\text { Of Those Saying Item(s) } \\
\text { Added More Time, \% } \\
\text { Who Found Item(s) Useful }\end{array}$ \\
\hline Delirium & 6 & 61.3 & 100.0 \\
Body control & 2 & 77.4 & 57.1 \\
Range of motion & 6 & 77.4 & 85.7 \\
Indicators of depression & 22 & 38.7 & 100.0 \\
Behavioral symptoms & 4 & 61.3 & 91.7 \\
Change in mood/behavior & 2 & 77.1 & 100.0 \\
Diseases & 8 & 87.1 & 100.0 \\
Problem condition & 3 & 83.9 & 80.0 \\
Pain & 5 & 84.5 & 78.6 \\
Skin condition & 8 & 87.1 & 100.0 \\
Foot care & 6 & 83.9 & 80.0 \\
Treatments & 6 & 83.9 & 100.0 \\
Mood, behavior programs & 8 & 90.3 & 100.0 \\
Rehabilitative/restorative care & 13 & 90.3 & 100.0 \\
\hline
\end{tabular}

In almost every instance where more time was said to be required, $80 \%$ or more of the assessors indicated that the items were clinically useful and should be included in the revised MDS. In terms of assessment time for the original MDS, the median assessment time for the full process was 60 minutes; the arithmetic average was 80 minutes. The increase in time commitment required to complete the expanded MDS 2.0 item set equaled 15 minutes per case.

\section{DISCUSSION}

The findings reported in this paper support the reliability and clinical utility of the new items incorporated by HCFA in Version 2.0 of the MDS; reliability levels for new items were adequate whereas the levels for many of the old items improved. As Version 2.0 of the MDS goes into wide use we should see an improvement in the accuracy of assessments. This will be reflected both in a general increase in item reliability and in a series of specific item improvements that will facilitate the identification of key clinical problems. Examples of the latter include better measures of mood, delirium, contractures, and balance, with a new ability to identify residents with behavior problems that do not respond to treatment, a variety of skin and foot problems, infections, and pain.

With these changes to the MDS, HCFA has carried through on its promise to update the MDS system. At the same time, however, HCFA also recognizes that future modifications in the MDS may be required; the item content of today's Version 2.0 may require additional supplementation in the future. For example, clinical practice standards could change as a result of scientific breakthroughs or altered reimbursement patterns; or nursing facilities may become primary sites of care for entirely new patient populations. As such changes occur, HCFA will be required to consider whether a new release of the MDS - Version 3.0 -will eventually need to be considered, perhaps by the turn of the century. The following set of factors would be considered in determining when work should begin on developing Version 3.0.

First, the speed at which the nursing home industry is able to incorporate the changes in Version 2.0 of the RAI is of paramount importance. There has always been a general agreement that HCFA should not mandate major system changes without also permitting some intervening "breathing period." In discussions with industry representatives during the process of creating MDS 2.0, 24 months was seen as the minimum time needed for facility staff to absorb the concepts that underpin a revised MDS and to evaluate its utility. If this proves to be the case, then with the 12 to 18 -month period required to draft and field test a new version, there will be a period of approximately 4 to 5 years between major revisions of the MDS.

Second, while the costs of instituting change need to be recognized, there can also be a substantial cost associated with not changing the RAI - the cost of complacency and lost opportunity. Residents should benefit as the MDS is changed to better reflect their needs and status; Version 2.0 is now serving that purpose, and the same goals will surely apply to Version 3.0.

Finally, changes in the structure of the nursing home industry and the population it serves will also have a substantial effect on the time-line for instituting changes to the MDS. If, for example, facilities begin serving large new populations (e.g., a major movement into rehabilitative based, subacute (are), this may increase the demand for new assessment items, which could accelerate initiation of work on MDS Version 3.0. For example, as clients who have been served in other sectors come into nursing homes (e.g., rehabilitation patients) or as nursing home patients enter other systems (e.g., home care), there will be a need to review the potential applicability of items from assessment systems used in these other environments. For example, in rehabilitation we would review the item set of the FIM measurement system.

In summary, HCFA has met the Congressional mandate to introduce a clinically useful assessment system. The first major changes to that system have been implemented, and HCFA has set in motion a plan for systematic, rationale change in the future. More specific information on RAI Version 2.0 can be found in the State Operations Manual Transmittal No. 272, April, 1995, and in the Long-Term Care Resident Assessment Instrument User's Manual, Ver- 
sion $2.0 .^{10}$ The reliability of the vast majority of items in this key clinical assessment system has been well established. For many of the old MDS items, reliability levels have improved; for almost all of the new items, reliability levels have been shown to be adequate. The measurement approach is being followed consistently in most nursing facilities, and these data have broad applicability in many clinical and management systems. At the same time, this does not mean that all MDS items pass the .75 criterion for excellence in reliability. Some concepts have been shown to be more difficult to assess, and a small number of key indicators have lower reliability levels. Examples of such items include the presence of end stage disease (weighted Kappa $=.58$ ), presence of foot problems (.52), side vision problems. (.19), delusions (.52), and hallucination (.49). Thus, as with any comprehensive measurement system, it is crucial to consider the accuracy of the assessment for specific items. While items with lower reliabilities have been included because of clinical necessity, such items are not good candidates for inclusion in other systems, e.g., reimbursement and quality indicator systems.

\section{REFERENCES}

1. Morris JN, Hawes C, Fries BE et al. Designing the national resident assessment instrument for nursing homes. Gerontologist 1990;30:293-307.

2. Morris JN, Hawes C, Murphy K et al., eds. Resident Assessment Instrument Training Manual and Resource Guide. Baltimore, MD: HCFA, 1991.

3. Hawes C, Morris JN, Phillips CD et al. Reliability estimates for the minimum data set for nursing home resident assessment and care screening. Gerontologist 1995;35:172-178.

4. Hawes $C$, Phillips $C D, M o r ~ V$ et al. The nursing home resident assessment nstrument and its effects on process quality. J Am Geriatr Soc 1997;45:97798.5.

5. Morris JN, Fries BE, Mehr DR et al. MDS cognitive performance scale. J Gerontol: Med Sci 1994;49:M174-182.

6. Mor V, Branco K, Fleishman J et al. The structure of social engagement among nursing home residents. J Gerontol: Psychol Sci 1995;50B:P1-8.

7. Brandeis GH, Berlowitz DR, Hossain M, Morris JN. Pressure ulcers: The Minimum Data Set and the resident assessment protocol. Adv Wound Care $1995 ; 8: 18-25$.

8. Brandeis GH, Baumann MM, Hossain $\mathrm{M}$ et al. The prevalnce of potentially remediable urinary incontinence in frail older people: A study using the Minimum Data Set. J Am Geriatr Soc 1997;45:179-184.

9. Fleiss JL. Statistical Methods for Rates and Proportions, 2nd Ed. New York: John Wiley \& Sons, 1981.

10. Morris JN, Murphy K, Nonemaker S. Long Term Care Resident Assessment Instrument User's Manual, Version 2.0. Baltimore, MD: HCFA, 1995. 